Western University

Scholarship@Western

\title{
Corrigendum to "Overlapping and distinct brain regions involved in estimating the spatial position of numerical and non-numerical magnitudes: An fMRI study" [Neuropsychologia 51(5) (2013) 979-989]
}

\author{
Stephan E. Vogel \\ Numerical Cognition Laboratory, Department of Psychology \& Brain and Mind Institute, The University of \\ Western Ontario, Westminster Hall, Room 325, London, Ontario, Canada N6A $3 K 7$. \\ Roland H. Grabner \\ Institute for Behavioral Sciences, ETH, Zurich, Switzerland; Department of Psychology, Georg-August- \\ University of Göttingen, Germany. \\ Michael Schneider \\ Department of Psychology, University of Trier, Germany. \\ Robert S. Siegler \\ Department of Psychology, Carnegie Mellon University, United States; SCIL Center, Beijing Normal \\ University, Beijing, China. \\ Daniel Ansari \\ Numerical Cognition Laboratory, Department of Psychology \& Brain and Mind Institute, The University of

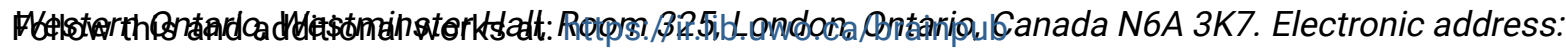 \\ 7iel.ansari@uwo.ca.,daniel.ansari@uwo.ca \\ Part of the Neurosciences Commons, and the Psychology Commons
}

Citation of this paper:

Vogel, Stephan E.; Grabner, Roland H.; Schneider, Michael; Siegler, Robert S.; and Ansari, Daniel, "Corrigendum to "Overlapping and distinct brain regions involved in estimating the spatial position of numerical and non-numerical magnitudes: An fMRI study" [Neuropsychologia 51(5) (2013) 979-989]" (2017). Brain and Mind Institute Researchers' Publications. 612.

https://ir.lib.uwo.ca/brainpub/612 
Corrigendum

\title{
Corrigendum to "Overlapping and distinct brain regions involved in estimating the spatial position of numerical and non-numerical magnitudes: An fMRI study" [Neuropsychologia 51(5) (2013) 979-989]
}

\author{
Stephan E. Vogel ${ }^{\mathrm{a}}$, Roland H. Grabner ${ }^{\mathrm{b}, \mathrm{e}}$, Michael Schneider ${ }^{\mathrm{c}}$, Robert S. Siegler ${ }^{\mathrm{d}, \mathrm{f}}$, \\ Daniel Ansari ${ }^{\mathrm{a}, *}$ \\ a Numerical Cognition Laboratory, Department of Psychology \& Brain and Mind Institute, The University of Western Ontario, Westminster Hall, Room 325, \\ London, Ontario, Canada N6A 3 K7 \\ b Institute for Behavioral Sciences, ETH, Zurich, Switzerland \\ ${ }^{\mathrm{c}}$ Department of Psychology, University of Trier, Germany \\ d Department of Psychology, Carnegie Mellon University, United States \\ e Department of Psychology, Georg-August-University of Göttingen, Germany \\ ${ }^{\mathrm{f}}$ SCIL Center, Beijing Normal University, Beijing, China
}

The authors wish to report an error in the method section of this manuscript. In this manuscript we mistakenly reported “...that the visual indicator of the trackball was reset to the centre of the screen (i.e., same location as the presented probe) after each trial in all experimental conditions (pp. 982)." Contrary to what we reported in the method section, the position of the trackball-cursor was set to a randomly selected position, excluding the correct position of the probes, along the number line at the start of every trial. As such the distance from the starting point of the trackball-cursor to the correct position of the probe on the physical line was randomly distributed across the experiment.

The authors would like to apologise for any inconvenience caused.

\footnotetext{
DOI of original article: http://dx.doi.org/10.1016/j.neuropsychologia.2013.02.001

* Corresponding author.

E-mail addresses: daniel.ansari@uwo.ca, daniel.ansari@gmail.com (D. Ansari).
} 